\title{
Sleep-Related Laryngospasm Caused by Gastroesophageal Reflux
}

\author{
Cheol Won Jang ${ }^{1}$, Zoon-Yup Kim ${ }^{2}$, Ki-Hwan Ji ${ }^{2}$ \\ ${ }^{1}$ Mackenzie Hwamyung Ilsin Christian Medical Center, Busan, \\ ${ }^{2}$ Department of Neurology, Busan Paik Hospital, Inje University College of Medicine, Busan, Korea
}

\section{위식도역류로 인한 수면관련성대문연축}

장철원, 김준엽 ${ }^{2}$, 지기환 ${ }^{2}$

멕켄지 화명일신기독병원, ${ }^{1}$ 인제대학교 의과대학 부산백병원 신경과 ${ }^{2}$

\author{
Received November 10, 2015 \\ Revised December 15, 2015 \\ Accepted December 15, 2015 \\ Address for correspondence \\ Ki-Hwan Ji, MD \\ Department of Neurology, Busan \\ Paik Hospital, Inje University \\ College of Medicine, 75 Bokji-ro, \\ Busanjin-gu, Busan 47392, Korea \\ Tel: +82-51-890-8769 \\ Fax: +82-51-890-6130 \\ E-mail: kihwanji@gmail.com
}

Sleep-related laryngospasm is a rare cause of sleep-related breathing disturbance which produce stridor or interruption of airflow associated with a distinct polysomnography arousal pattern. We report a case of a sixty-five-year-old woman who was referred for awakenings with abrupt respiratory distress and fear of suffocation. A polysomnography showed a total or near-total cessation of airflow, followed by choking and stridor for several minutes with a rapid increase in heart rate. Temporary hoarseness was seen. The esophageal $\mathrm{pH}$ monitoring indicated acid reflux, which confirmed gastroesophageal reflux disease. The protonpump inhibitor eliminated the sleep-related laryngospasm.

J Sleep Med 2016;13(1):28-30
수면 중 발생하는 호흡장애 대부분은 수면무호흡증이 원 인이다. 드문 호흡장애의 원인 중 임상적으로 감별해야 하는 질환이 수면관련성대문연축(sleep-related laryngospasm)이 다. 기관근육의 기능장애나 기관 옆 연조직(paratracheal softtissue)의 부기(swelling)는 수면 중 각성을 유발시키며, 호흡 을 방해하고 천명(stridor)을 발생시킨다. 후두 천명은 흡기 시에 발생하는 고음의 거친 호흡음이다. 수면 중 발생하는 비교적 짧은 기간의 호흡 중단 뒤 천명이 수분간 지속하고, 환자는 공황발작이나 질식에 대한 극심한 공포, 청색증 등을 나타낼 수 있다. ${ }^{1}$ 저자는 최근 수면다원검사를 통해 전형적 인 수면관련성대문연축의 임상양상을 확인하였고, 위식도 내시경과 24시간 식도 산도 검사를 통해 위식도역류를 진단 후 위식도역류에 유발된 수면관련성대문연축을 치료하였기 에 이를 보고하는 바이다.

This is an Open Access article distributed under the terms of the Creative Commons Attribution Non-Commercial License (http://creativecommons.org/licenses/by-nc/3.0) which permits unrestricted non-commercial use, distribution, and reproduction in any medium, provided the original work is properly cited.

\section{증 례}

65세 여자가 한 달 전부터 수면 중 갑자기 숨이 막히는 느 낌이 들면서 깬 후 숨을 쉬기가 힘들고, 가슴이 뛰며, 기침을 심하게 하고 목이 쉬는 증상이 수분간 지속한다며 병원에 왔다. 1 주 전부터는 거의 매일 증상이 발생하여 최근에는 잠 이 들기가 무섭다고 하였다. 만성기침, 가슴 통증, 속 쓰림은 없다고 하였다. 증상은 주로 수면 후 2 3시간이 지나서 발 생한다고 하였다. 평소 건강한 편으로 복용하는 약은 없었 다. 신경학적 진찰은 정상이었으며, 뇌전증을 의심할 만한 병력은 없었다. 신장 $156 \mathrm{~cm}$, 체중 $61 \mathrm{~kg}$ 으로 체질량지수는 $25.07 \mathrm{~kg} / \mathrm{m}^{2}$ 였고 최근 체중변화는 없었다. 하루에 한 잔 정 도 커피를 마시고, 음주나 흡연은 하지 않았다. 평소 오후 9 시경 잠자리에 들고 4시경 기상하고, 가벼운 코골이는 있지 만, 무호흡 여부는 알지 못했다. 수면관련성대문연축을 감별 하기 위해서 시행한 이비인후과적 진찰과 후두경에서, 후비 루(postnasal drip)나 기관근육의 병터나 기능장애는 확인되 지 않았다. 천식과 감별을 위해 시행한 검사도 정상이었다. 신물이 넘어오는 등 위식도역류질환을 의심할 만한 병력은 
없었다. 수면다원검사는 23시부터 6시 20분까지 진행하였 고, 뇌파의 전극은 국제 10-20법에 따랐다. 수면잠복기는 21 분 30 초, 렘수면 잠복기는 2 시간 58 분, 총 수면 시간은 6시간 17 분으로, 수면 효율은 85.2\%였다. 전체 수면 중 수면1단계 (N1)가 $14.72 \%$ 로 증가하였고, 수면2단계(N2)는 59.3\%였다. 수면3단계(N3)는 없었고, 렘수면은 26\%였다. 무호흡-저호 흡 지수(apnea-hypopnea index)는 $9.2 / \mathrm{h}$ 로 경한 수면무호
흡이었다. 각성지수는 $11.9 / \mathrm{h}$ 로 정상범위였다. 주기적사지 운동지수는 $19.7 / \mathrm{h}$ 로 증가하여 있었다. 새벽 12 시 16 분경 한 차례 증상이 발생하였다. 증상 발생 직전 저호흡이 선행하였 고, 환자가 수면2단계(N2)에서 갑자기 깬 후 호흡 노력에도 불구하고 20여 초간 호흡의 중단이 발생하였다(Fig. 1). 이후 심한 천명과 함께 안절부절못하는 양상을 보였다. 심장박동 이 증가하였으나, 심한 저산소 혈증과 청색증은 동반하지 않

\section{I}

EEG

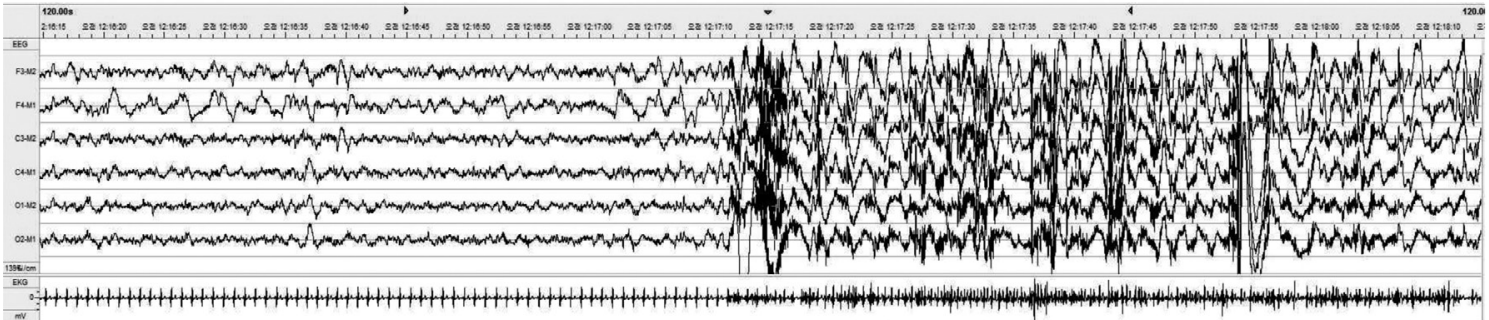

EKG

Nasal flow

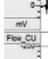

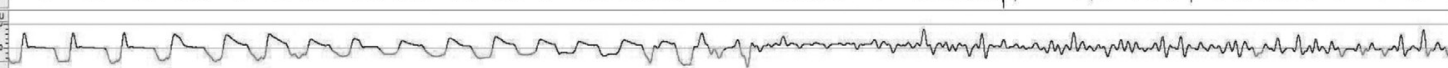
Nasal pressure

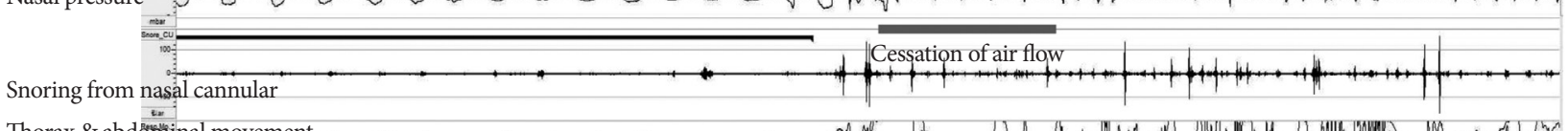
Thorax \& abdơninal movement

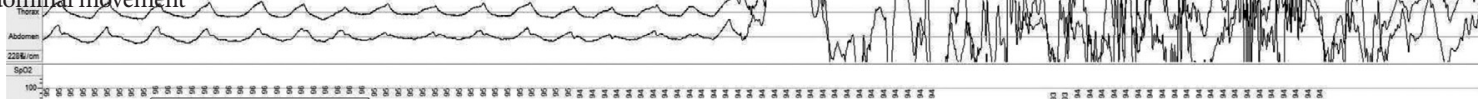
Oxygen saturation Heart rate $100 \frac{1}{10}=$

Figure 1. One-hundred-twenty-second excerpts from a polysomnography. Patient woke up from hypopnea during N2 and had a total or near-total cessation of airflow. Note the increased heart rates during the event. The black arrow indicates the beginning of the event. The thick line below the nasal pressure indicates cessation of air flow. EEG: electroencephalography, EKG: electrocardiography.

EEG
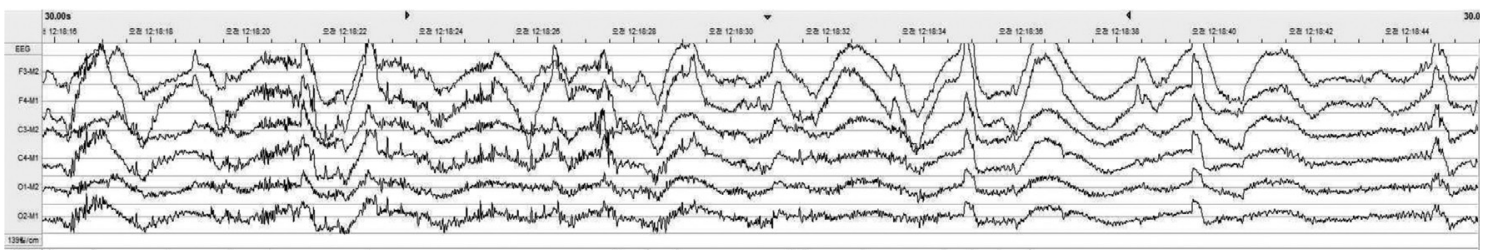

EKG

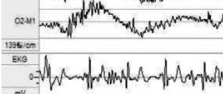

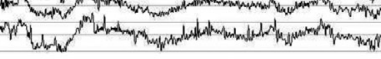

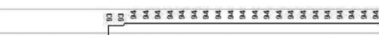


았다(Fig. 2). 천명은 약 3분간 지속하였고, 그동안 목소리를 내지 못하였다. 증상 이후 얼마간 목 주위 불편감을 호소하 면서 쉰 목소리를 내었다. 임상적으로 뚜렷한 속 쓰림 증상은 없었지만, 위식도역류질환으로 인한 수면관련성대문연축을 감별하기 위해 위식도 내시경과 보행성 24시간 식도산도 검 사를 시행하였고, 위식도역류를 확인하였다. 환자는 약 3개 월간 양성자 펌프억제제(proton pump inhibitor)를 복용하 였고, 약 복용 후 증상의 재발은 없었다.

\section{고 찰}

수면관련성대문연축은 천명음을 나타내기 때문에 신경계 퇴행성질환인 다계통위축증의 감별이 필요하다. 하지만 다 계통위축증이 파킨슨증, 소뇌기능장애, 자율신경기능장애, 추체계 증상의 조합으로 나타나기 때문에 임상양상으로 구 분이 가능하다. 신경계퇴행성질환과 관련이 없는 수면관련 성대문연축의 병태생리는 거의 알려진 바가 없으나, 기관 근 육의 기능장애, 후비루, 위식도역류에 의한 상기도 연조직 자극에 의한다고 알려졌다. 천명이 코골이로 의심될 수 있으 나 수면다원검사를 통해서 흡기시 발생하는 고음의 거친 호 흡음을 확인하면 감별할 수 있다. ${ }^{2}$ 드물게 성대문연축으로만 발생한 뇌전증의 보고가 있어 주의가 필요하다. ${ }^{3}$ 수면무호흡 이 수면 중 각성을 유발하고, 숨막힘이나 헉헉거림의 양상을 보일 수 있으나, 수면관련성대문연축과 같이 수분간 천명이 지속되거나 극심한 공포를 유발하지는 않는다. 소아에서 발 생하는 야경증(sleep terror)도 비슷한 양상을 나타낼 수 있으 나 호흡기 증상이 주된 증상은 아니며, 공황발작은 주로 주 간에 발생하는 점이 감별에 유용하다. ${ }^{1}$

증례의 경우 신경학적 소견으로 다계통위축증을 시사하 는 임상양상은 보이지 않았고, 후비루나 기관 근육의 병터나 기능장애는 없었다. 또한 수면다원검사시 국제 10-20법에 따라 전극을 부착하고 뇌파를 기록하였으나 증상발생시와 증상 전후 뇌전증모양 방전(epileptiform discharge)이 확인 되지 않았고, 위식도 내시경과 24시간 식도산도 검사로 위식 도역류를 확인하였고, 양성자 펌프억제제 복용 후 증상의 재 발이 없었던 점을 종합하여 위식도역류에 유발된 수면관련 성대문연축으로 진단할 수 있었다.

수면관련성대문연축과 위식도역류와의 연관성은 꾸준히 제기되어 왔다. ${ }^{45}$ 최근 수면다원검사와 식도산도 검사를 동 시에 시행하여 위식도역류가 발생시 성대문연축이 발생함 을 확인한 바 있으나, ${ }^{6}$ 수면관련성대문연축이 드문 질환이고,
수면다원검사와 침습적인 식도산도 검사를 동시에 시행하 는 것이 임상적으로 어렵고, 검사를 시행한다 해도 증상의 재 현이 드물어서 위식도역류가 직접 수면관련성대문연축의 원 인이 됨을 밝히는 것은 어렵다. 또한 위식도역류가 수면 중 증상을 나타내는 경우가 드물며, 식도산도 검사를 통해 확인 되지 않는 경우도 있어 인과관계를 입증하기 쉽지 않다. ${ }^{6.7}$ 본 증례에서는 위식도역류를 치료한 후 수면관련성대문연축 의 증상이 재발하지 않았으므로 두 상태가 관련이 있었던 것 을 간접적으로 밝힐 수 있었다.

위식도역류가 증상을 유발하는 기전은 해부학적으로 후두 와 근위부 식도가 근접해 있어 펩신과 담즙산이 후두로 역류 하여 직접적인 자극, 조직 염증을 일으켜 증상을 유발하거나 하부 식도의 위산역류가 미주신경을 매개로 한 반사작용을 일으켜 증상을 유발할 수 있다. 후두의 점막은 정상적으로 위 산과 접촉되지 않으며 타액에 의하여 중화될 수 없어 역류한 위 내용물에 대한 방어기전이 매우 약하다. 또한 밤에는 상부 식도괄약근의 압력이 낮에 비하여 낮고, 기침과 타액분비와 같은 다른 방어기전도 약해져 위 내용물이 인후로 역류하여 부종이나 염증과 같은 손상이 쉽게 일어날 수 있다. ${ }^{8}$

본 증례는 국내에서는 처음으로 수면관련성대문연축 환자 를 수면다원검사와 24시간 식도산도 검사를 통해 진단하고 양성자 펌프억제제를 사용하여 치료한 사례로 임상적인 의 미가 있으며, 앞으로 이에 대한 더 많은 연구와 경험이 필요 하다.

\section{REFERENCES}

1. American Academy of Sleep Medicine. The international classification of sleep disorders: diagnostic and coding manual. 2nd ed. Westchester: American Academy of Sleep Medicine, 2005;239-241.

2. Kavey NB, Whyte J, Blitzer A, Gidro-Frank S. Sleep-related laryngeal obstruction presenting as snoring or sleep apnea. Laryngoscope 1989; 99(8 Pt 1):851-854.

3. Murray RC, Powell D, Curry JM, Sperling MR, Evans JJ, Spiegel JR. Epileptic laryngospasm presenting as a primary sleep disturbance. Arch Otolaryngol Head Neck Surg 2010;136:1025-1027.

4. Aloe FS, Thorpy MJ. Sleep-related laryngospasm. Arq Neuropsiquiatr 1995;53:46-52.

5. Thurnheer R, Henz S, Knoblauch A. Sleep-related laryngospasm. Eur Respir J 1997;10:2084-2086.

6. Roland MM, Baran AS, Richert AC. Sleep-related laryngospasm caused by gastroesophageal reflux. Sleep Med 2008;9:451-453.

7. Iriarte J, Urrestarazu E, Alegre M, Goñi C, Viteri C, Artieda J. Sleeprelated laryngospasm: a video-polysomnographic recording. Epileptic Disord 2006;8:70-72.

8. Fass R, Achem SR, Harding S, Mittal RK, Quigley E. Review article: supra-oesophageal manifestations of gastro-oesophageal reflux disease and the role of night-time gastro-oesophageal reflux. Aliment Pharmacol Ther 2004;20 Suppl 9:26-38. 